Fixed Point Theory, 23(2022), No. 1, 351-370

DOI: $10.24193 /$ fpt-ro.2022.1.22

http://www.math.ubbcluj.ro/ ${ }_{\text {nodeacj/sfptcj.html }}$

\title{
SOLVING THE SPLIT EQUALITY HIERARCHICAL FIXED POINT PROBLEM
}

\author{
B. DJAFARI-ROUHANI ${ }^{1}$, K.R. KAZMI ${ }^{2}$, S. MORADI ${ }^{3}$, REHAN ALI ${ }^{4}$ AND S.A. KHAN ${ }^{5}$ \\ ${ }^{1}$ Department of Mathematical Sciences, University of Texas at El Paso, \\ 500W. University Ave., El Paso, Texas 79968, USA \\ E-mail: behzad@utep.edu \\ ${ }^{2}$ Department of Mathematics, Faculty of Science and Arts - Rabigh, King Abdulaziz University, \\ P.O. Box 344, Rabigh 21911, Kingdom of Saudi Arabia \\ and \\ Department of Mathematics, Aligarh Muslim University, Aligarh 202002, India \\ E-mail: krkazmi@gmail.com \\ (Corresponding author) \\ ${ }^{3}$ Department of Mathematics, Faculty of Sciences, Lorestan University, \\ Khorramabad, 68151-4-4316, Iran \\ E-mail: moradi.s@lu.ac.ir \\ ${ }^{4}$ Department of Mathematics, Jamia Millia Islamia, New Delhi 110025, India \\ E-mail: rehan08amu@gmail.com \\ ${ }^{5}$ Department of Mathematics, BITS-Pilani, Dubai Campus, \\ P.O. Box 345055, Dubai, United Arab Emirates \\ E-mail: khan.math@gmail.com
}

\begin{abstract}
This paper deals with a split equality hierarchical fixed point problem in real Hilbert spaces which is an important and natural extension of hierarchical fixed point problem and split equality fixed point problem. An iterative algorithm where the stepsizes do not depend on the operator norms, so called simultaneous Krasnoselski-Mann algorithm is suggested for solving the split equality hierarchical fixed point problem. Further we prove a weak convergence theorem for the sequence generated by this algorithm. This special aspect of the algorithm together with the convergence result makes it an interesting scheme. Furthermore, we give some examples to justify the main result. Finally, we show that our purposed iterative algorithm is more efficient than some other known iterative algorithms. On the other hand, the framework is general and allows us to treat in a unified way several iterative algorithms, recovering, developing and improving some recently known related convergence results in the literature.

Key Words and Phrases: Split equality hierarchical fixed point problem, split equality fixed point problem, maximal monotone operator, simultaneous Krasnoselski-Mann algorithm, weak convergence, weak convergence.

2020 Mathematics Subject Classification: 47H09, 47H10, 47J25, 54H25.
\end{abstract}




\section{ACKNOWLEDGMent.}

Authors are thankful to the anonymous referees for their critical comments which led to substantial improvements in the original version of the manuscript.

\section{REFERENCES}

[1] H. Attouch, Variational Convergence for Functions and Operators, Applicable Mathematics Series, Pitman (Advanced Publishing Program), Boston, MA, 1984.

[2] H. Attouch, J. Bolte, P. Redont, A. Soubeyran, Alternating proximal algorithms for weakly coupled minimization problems, Applications to Dynamical Games and PDEs, J. Convex Anal., 15(2008), 485-506.

[3] H.H. Bauschke, P.L. Combettes, Convex Analysis and Monotone Operator Theory in Hilbert Spaces, Springer Science, New York, 2011.

[4] H. Brézis, Operateurs Maximaux Monotones et Semi-groupes de Contractions dans les Espaces de Hilbert, North Holland Mathematics Studies, No. 5, North Holland, Amsterdam, 1973.

[5] C. Byrne, A unified treatment of some iterative algorithms in signal processing and image reconstruction, Inverse Probl., 20(2004), 103-120.

[6] Y. Censor, T. Bortfeld, B. Martin, A. Trofimov, A unified approach for inversion problems in intensity modulated radiation therapy, Physics in Medicine and Biology, 51(2006), 2353-2365.

[7] S.-S. Chang, J.C. Yao, C.F. Wen, L.C. Zhao, On the split equality fixed point problem of quasipseudo-contractive mappings without a prior knowledge of operator norms with applications, J. Optim. Theory Appl., 185(2020), no. 2, 343-360.

[8] H. Cui, L.C. Ceng, Iterative solutions of the split common fixed point problem for strictly pseudo-contractive mappings, J. Fixed Point Theory Appl., 20(2018), no. 2, Art.92, pp. 12.

[9] Q.L. Dong, S. He, J. Zhao, Solving split equality problem without prior knowledge of operator norms, Optimization, 64(9)(2015), 1887-1906.

[10] Q.L. Dong, K.R. Kazmi, R. Ali, X.H. Li, Inertial Krasnoseski-Mann type hybrid algorithms for solving hierarchical fixed point problems, J. Fixed Point Theory Appl., 21(2019):57 (https://doi.org/10.1007/s11784-019-0699-6).

[11] M. Eslamian, Y. Shehu, S.O. Iyioda, A strong convergence theorem for a general split equality problem with applications to optimization and equilibrium problem, Calcolo 55(2018), no. 4, Art. 48, pp.31.

[12] K. Goebel, W.A. Kirk, Topics in Metric Fixed Point Theory, Cambridge Studies in Advanced Mathematics, 28, Cambridge University Press, Cambridge, 1990.

[13] K.R. Kazmi, R. Ali, M. Furkan, Krasnoselski-Mann type iterative method for hierarchical fixed point problem and split mixed equilibrium problem, Numer. Algorithms, 77(2018), 289-308.

[14] K.R. Kazmi, R. Ali, M. Furkan, Hybrid iterative method for split monotone variational inclusion problem and hierarchical fixed point problem for a finite family of nonexpansive mappings, Numer. Algorithms, 79(2018), 499-527.

[15] K.R. Kazmi, R. Ali, S. Yousuf, M. Shahzad, A hybrid iterative algorithm for solvingmonotone variational inclusion and hierarchical fixed point problems, Calcolo, 56(2019):34 (https://doi.org/10.1007/s10092-019-0331-6).

[16] K.R. Kazmi, S. Yousuf, R. Ali, Systems of unrelated generalized mixed equilibrium problems and unrelated hierarchical fixed point problems in Hilbert space, Fixed Point Theory, 21(2020), no. 2, 611-630.

[17] G. Lopez, V. Martin-Marquez, F. Wang, H.K. Xu, Solving the split feasibility problem without prior knowledge of operator norms, Inverse Probl., 28(2012), 085004.

[18] Z.Q. Luo, J.S. Pang, D. Ralph, Mathematical Programs with Equilibrium Constraints, Cambridge University Press, 1996.

[19] A. Moudafi, Krasnoselski-Mann iteration for hierarchical fixed-point problems, Inverse Probl., 23(2007), 1635-1640.

[20] A. Moudafi, Alternating CQ-algorithm for convex feasibility and split fixed point problems, J. Nonlinear Convex Anal., 15(2014), 809-818. 
[21] A. Moudafi, E. Al-Shemas, Simultaneous iterative methods for split equality problems, Trans. Math. Program. Appl., 1(2013), no. 2, 1-11.

[22] A. Moudafi, P.-E. Maige, Towards viscosity approximations of hierarchical fixed-point problems, Fixed Point Theory Appl., 2006(2006), Article ID 95453, pp. 10.

[23] A. Moudafi, P.-E. Mainge, Strong convergence of an iterative method for hierarchical fixed-point problems, Pacific J. Optim., 3(2007), 529-538.

[24] Z. Opial, Weak convergence of the sequence of successive approximations for nonexpansive mappings, Bull. Amer. Math. Soc., 73(1967), 591-597.

[25] X. Qin, J.C. Yao, A viscosity iterative method for a split feasibility problem, J. Nonlinear Convex Anal., 20(2019), no. 8, 1497-1506.

[26] R.T. Rockafellar, J.-B. Wets, Variational Analysis, Grundlehren der Mathematischen Wissenschaften, 317, Springer-Verlag, 1998.

[27] I. Yamada, N. Ogura, Hybrid steepest descent method for the variational inequality problem over the fixed point set of certain quasi-nonexpansive mappings, Numer. Funct. Anal. Optim., $\mathbf{2 5}(2004), 619-655$.

[28] Q. Yang, J. Zhao, Generalized KM theorem and their applications, Inverse Probl., 22(2006), 833-844.

[29] Y. Yao, Y.C. Liou, Weak and strong convergence of Krasnoselski-Mann iteration for hierarchical fixed-point problems, Inverse Probl., 24(2008), 501-508.

[30] J. Zhao, Solving split equality fixed point problem of quasi-nonexpansive mappings without prior knowledge of operator norms, Optimization, 64(2015), 2619-2630.

[31] J. Zhao, Y. Jia, H. Zhang, General alternative regularization methods for split equality common fixed-point problem, Optimization, 67(2018), 619-635.

Received: May 16, 2020 ; Accepted: January 28, 2021. 
B. DJAFARI-ROUHANI, K.R. KAZMI, S. MORADI, REHAN ALI AND S.A. KHAN 